\title{
Effects of intracoronary and intravenous amrinone infusions in patients with cardiac failure and patients with near normal cardiac function
}

\author{
P T WILMSHURST, D S THOMPSON, S M JUUL, H C DITTRICH, J R DAWSON, \\ J $M$ WALKER, B S JENKINS, D J COLTART, $M M$ WEBB-PEPLOE \\ From the Department of Cardiology, St Thomas's Hospital, London
}

SUMMARY The effects of intracoronary and intravenous infusions of amrinone were studied to distinguish the drug's direct cardiac actions from its peripheral vascular and neuroendocrine properties. Intracoronary infusions of amrinone were found to have no haemodynamic effect other than producing a slight reduction in the left ventricular ejection fraction and some suggestion of coronary vasodilatation in patients with impaired left ventricular function. They did not improve contractility, cardiac output, or filling pressures and had no significant effect on myocardial metabolism, although therapeutic concentrations of the drug were detected in coronary sinus blood. Intravenously administered amrinone reduced filling pressures and improved the cardiac index in all patients, but haemodynamic improvements were most pronounced in the patients with the worst cardiac function. These changes were accompanied by improvements in the indices of contractility only in patients in whom alterations in concentrations of free fatty acid, glycerol, and glucose suggested peripheral catecholamine release. In the patients with the best basal cardiac function intravenously administered amrinone produced a reduction in myocardial work and evidence of myocardial ischaemia, as a result of excessive reduction of coronary perfusion pressure and increased heart rate, without any appreciable increase in cardiac index.

It is concluded that, at the concentrations of the drug that can be achieved in man without adverse effects, amrinone has no direct positive inotropic effect. Haemodynamic changes are predominantly the result of vasodilatation, although catecholamines may be released in some patients.

Amrinone (Inocor; Winthrop-Breon, USA) is the prototype of a group of new drugs that are currently being investigated for use in the treatment of patients with heart failure. Amrinone acutely lowers cardiac filling pressures and improves cardiac output ${ }^{1}$ without increasing myocardial oxygen consumption. ${ }^{23}$ These effects have been largely attributed to the direct positive inotropic action that has been shown with the drug in normal animal myocardium. ${ }^{4} 5$ Relatively less attention has been paid to the direct vasodilator properties of amrinone. 56

In patients with cardiac failure initial small studies showed an improvement in a contractility index

Requests for reprints to Dr P T Wilmshurst, Department of Cardiology, St Thomas's Hospital, London SE1 7EH.

Accepted for publication 3 January 1984 (maximum rate of rise of left ventricular pressure (dP/dt max)) after intravenous administration of amrinone..$^{7-9}$ These studies contained flaws in experimental design, which we have discussed previously, ${ }^{10^{-12}}$ not least of these being the absence of any attempt to look for a dose response relation between the amount of amrinone administered and changes in contractility. Subsequent studies that sought a doseresponse relation and contained larger numbers of observations than the earlier reports found no evidence of a positive inotropic effect in patients. ${ }^{3} 1013$ Moreover, two of these subsequent studies compared the effects of amrinone with those of other agents commonly used in the treatment of cardiac failure. One study compared amrinone with dobutamine, ${ }^{13}$ which possesses both positive inotropic and vasodilator properties. The authors showed no change in contractility after amrinone but an increase (partially 
heart rate related) with dobutamine; both drugs also produced changes in haemodynamics attributable to vasodilatation. In the other study amrinone was compared with a pure vasodilator, nitroprusside. ${ }^{3}$ No difference between the effects of the two drugs was detected except for evidence that amrinone caused catecholamine release in some patients.

Because of this conflicting evidence and the difficulty of determining, by intravenous administration, the effect of drugs on the human myocardium in vivo we have investigated the effects of amrinone on the heart by administering it by intracoronary infusion.

\section{Patients and methods}

We studied eight men without significant coronary disease. Seven, aged 28-52 (mean 41) years, had dilated cardiomyopathy; of them, three gave a history of high alcohol intake. Six were in sinus rhythm and one in atrial fibrillation. All were receiving diuretics, six digoxin, and one each amiodarone, warfarin, and indomethacin. In addition, we studied a man aged 41 who gave a history of angina despite "normal coronary arteries and good left ventricular function" diagnosed at another hospital. He had been referred for investigation of the effect of atrial pacing on myocardial lactate extraction. He was receiving atenolol (100 $\mathrm{mg}$ daily) at the time of his investigation and had never been in cardiac failure. (Careful review of coronary angiograms after the trial showed that three patients with poor cardiac function had isolated noncritical coronary narrowings $(<50 \%)$, which were thought to be insufficient in number or site to account for their global cardiac dysfunction. The patient with angina was found to have a single $80 \%$ narrowing in a very small diagonal branch.) Current drug treatment was continued until the evening before the study. The trial had the approval of the hospital ethical committee, and each patient gave his informed written consent.

Patients were studied in the morning after an overnight fast. One hour before cardiac catheterisation they were premedicated with diazepam $(10 \mathrm{mg})$ and atropine $(0.6 \mathrm{mg})$ intramuscularly. Heparin $(45 \mathrm{U} / \mathrm{kg})$ was given intravenously at the same time to minimise the effect of a subsequent dose of heparin on free fatty acid concentrations. ${ }^{14}$ Right and left heart pressures were measured routinely via catheters in the right femoral vein and artery inserted under local anaesthesia with lignocaine. Immediately after arterial catheterisation a second dose of heparin ( $45 \mathrm{U} / \mathrm{kg}$ ) was given. Coronary arteriography was performed with Urografin $370(76 \%)$. The minimum volume of contrast (about five injections, each of 5-8 ml) was used.

A fluid filled catheter was then positioned in the pulmonary artery. A catheter tip micromanometer (No 8 French gauge Millar) was positioned in the left ventricle retrogradely across the aortic valve for measuring pressure and injecting contrast medium for left ventricular cineangiography. A selective left coronary Judkins's catheter was inserted via an additional arterial Seldinger puncture for intracoronary infusion of drugs and measurement of aortic pressure. Cardiac output was measured by dye dilution ${ }^{10}$ and coronary sinus flow by thermodilution, ${ }^{14}$ as previously described.

Pressures were measured with reference to the sternal angle as zero. Pressure, micromanometer, and thermistor signals were displayed on a Cambridge 12 channel recorder, stored on magnetic tape, and processed by computer. Indices of contractility, including $\mathrm{dP} / \mathrm{dt} \max , \mathrm{dP} / \mathrm{dt}$ max divided by developed pressure $(\mathrm{dP} / \mathrm{dt} \max / \mathrm{P}),{ }^{15}$ the peak measured shortening velocity of the contractile element $((\mathrm{dP} / \mathrm{dt} / \mathrm{P}) \max ),{ }^{16}$ and the product of the series elastic stiffness constant and the velocity of contractile shortening at zero load (KV max), ${ }^{17}$ were derived by on line computer processing of the pressure signal. ${ }^{10}$

The plasma concentrations of amrinone and its metabolite, $N$-acetyl amrinone, were determined by high pressure liquid chromatography. ${ }^{18}$ The oxygen content and concentrations of lactate, pyruvate, hydroxybutyrate, acetoacetate, glycerol, free fatty acid, and glucose in arterial and coronary sinus blood were determined as previously described. ${ }^{314}$

Myocardial oxygen consumption, left ventricular minute work, myocardial efficiency, and the myocardial extractions, extraction ratios, and oxygen extraction ratios of substrates were calculated using standard formulas. ${ }^{19}$ Total systemic vascular resistance was taken to be mean aortic pressure divided by cardiac output. Pulmonary vascular resistance was considered to be:

(Mean pulmonary artery pressure - diastolic pulmonary artery pressure)

cardiac output

Coronary vascular resistance was calculated from ${ }^{20}$ :

(Mean aortic diastolic pressure - left ventricular diastolic pressure) $\times$ coronary diastolic filling time

coronary sinus flow

No measurements were made until at least 40 minutes after coronary arteriography. The patient with angina was paced to determine the effect of fast heart rates on myocardial metabolism of lactate. He was allowed to return to the basal state before undergoing the research procedure.

During the research procedure haemodynamic 
measurements, blood sampling, and left ventricular cineangiography were performed according to a time schedule so that observations were made at comparable intervals after test interventions. The interventions were: (1) control or basal state, (2) intracoronary lactate infusion, (3) intracoronary amrinone infusion, (4) intravenous amrinone. The order of interventions 2 and 3 was randomised. The patients were unaware of the order of the interventions. To eliminate observer bias or selection haemodynamic indices (heart rate, blood pressures, flows, and contractility indices) were calculated by computer during predetermined intervals after the start of drug administration. Biochemical analysis was performed by automatic analysis (oxygen content and glucose concentration) or by technicians unaware of the nature of the samples for analysis.

Intracoronary amrinone was administered at a rate of $0.5 \mathrm{mg} / \mathrm{min}$. The lactate (carrier) solution used was identical in all respects to the amrinone solution except that it contained no amrinone. We have previously used this lactate solution in both in vitro ${ }^{6}$ and in vivo $^{3}$ experiments and shown it to be without vascular or myocardial activity. The lactate solution was administered at the same rate as the amrinone solution. Six patients received intracoronary infusions of amrinone and the lactate lasting two minutes each (short infusion). Three received intracoronary amrinone first and three the lactate first. In these six patients the measurements performed two minutes after the start of the infusion were made during the infusion. Other measurements were made after the end of the infusion. In two patients (one with good left ventricular function) both intracoronary infusions were prolonged for 15 minutes (long infusion) so that all measurements were made during infusion. One of these two patients (the one with good left ventricular function) received intracoronary amrinone first. (The number of studies of long intracoronary infusion was smaller than intended because the manufacturer of amrinone withdrew all our stocks of the drug before we had completed the trial.)

In the control state heart rate, pulmonary arterial, aortic, and left ventricular pressures, contractility indices, cardiac output, and coronary sinus flow were measured, and arterial (left ventricular) and coronary sinus blood was sampled for metabolite concentrations. Single plane left ventricular cineangiography (right anterior oblique projection) was performed for calculating left ventricular volumes and the end systolic pressure volume relation. About 20 minutes was allowed for return to the basal state, which was confirmed by rechecking pressures and contractility indices. The first intracoronary infusion was started and pressures and indices of left ventricular contractility measured every two minutes for six minutes. Eight minutes after starting the intracoronary infusion all measurements including those of flows and metabolite concentrations and left ventricular cineangiography were repeated. After permitting another return to the basal state the second intracoronary infusion was started with measurements and angiography at intervals identical to those used for the first intracoronary infusion. During each intracoronary infusion coronary sinus blood was sampled for measurement of amrinone concentration. Mixed venous blood was also sampled after the long infusions in the two patients who had received these.

After a further return to the basal haemodynamic state each subject was given $1.5 \mathrm{mg} / \mathrm{kg}$ intravenous amrinone over two minutes. Measurements and angiography were performed after the start of this infusion at the same intervals as those that had been used after the start of the intracoronary infusions. Peripheral venous blood was sampled for measurement of plasma amrinone concentration after intravenous amrinone.

\section{STATISTICAL ANALYSIS}

Data on the six patients with poor left ventricular function who received short intracoronary infusions are expressed as mean (SEM). Statistical analysis for this group was by the paired $t$ test. The initial control (basal) period was compared with the basal state before each intervention. The effects seen at all times after each intervention were compared with both the initial control period and the control period immediately before that intervention. In addition, the effects observed after intracoronary and intravenous infusion of amrinone were compared with the effects seen at the same intervals after intracoronary infusion of lactate.

The data on the two patients who received long intracoronary infusions were not amenable to statistical analysis, and the raw data are provided.

Further statistical analysis was by linear or log linear regression. Spearman's rank test was used to test for a non-parametric relation when one was sought but could not be detected using a simple algorithm. A p value of less than 0.05 was considered to be significant.

\section{Results}

\section{PLASMA AMRINONE CONCENTRATIONS}

Table 1 shows the concentrations of amrinone detected in coronary sinus blood during intracoronary infusions of amrinone in the patients studied. No $\mathrm{N}$-acetyl amrinone was detected in the coronary sinus blood of the patients during the infusions. Table 2, which shows our total experience of the range of concentrations of amrinone found in peripheral blood 

blood during infusion of intracoromary amrinone ( $0.5 \mathrm{mg} / \mathrm{min})$

\begin{tabular}{lll}
\hline $\begin{array}{l}\text { Case } \\
\text { No }\end{array}$ & $\begin{array}{l}\text { Length of } \\
\text { infusion }\end{array}$ & Amrinome ( $\mu \mathrm{g} / \mathrm{ml})$ \\
\hline 1 & Short & 0.18 \\
2 & Short & 1.37 \\
3 & Short & Detectable but \\
& unquantifiable \\
4 & Short & 0.69 \\
5 & Short & 1.70 \\
6 & Short & 1.60 \\
7 & Long & 2.07 \\
8 & Long & 2.45 \\
\hline
\end{tabular}

after infusion of 1.5 and $3.5 \mathrm{mg} / \mathrm{kg}$ intravenous amrinone and during long term oral treatment, is given for comparison. It should be noted that amrinone was detectable in venous blood after long intracoronary infusion in each of the two patients who received this, being $0.46 \mu \mathrm{g} / \mathrm{ml}$ in the patient with poor left ventricular function and $0.25 \mu \mathrm{g} / \mathrm{ml}$ in the patient with good left ventricular function.

\section{SHORT INFUSIONS}

\section{Haemodynamics}

The initial control (basal) values of all haemodynamic indices measured were the same as each set of prein-

Compared with control measurements the intracoronary infusions did not cause any alteration in heart rate, left ventricular pressures, or contractility indices either during the infusion or after the infusion had stopped (Fig. 1: only the contractility indices $\mathrm{dP} / \mathrm{dt} \max$ and $\mathrm{KV}$ max are shown; other contractility indices and $\mathrm{dP} / \mathrm{dt}$ min were also unaltered). Variables measured after intracoronary infusion, including coronary sinus flow, arteriocoronary sinus oxygen difference, myocardial oxygen consumption and efficiency (Fig. 2), cardiac index, left ventricular volumes and the left ventricular end systolic pressure to volume ratio (Fig. 3), and pulmonary arterial and aortic pressures, left ventricular minute work, and systemic and pulmonary vascular resistances (Fig. 4), were also unaltered by the intracoronary infusions.

When the intracoronary infusions of amrinone and lactate were compared no significant difference was
Table 1 Plasma concentrations of amoinone in cononary sinus tervention control values.
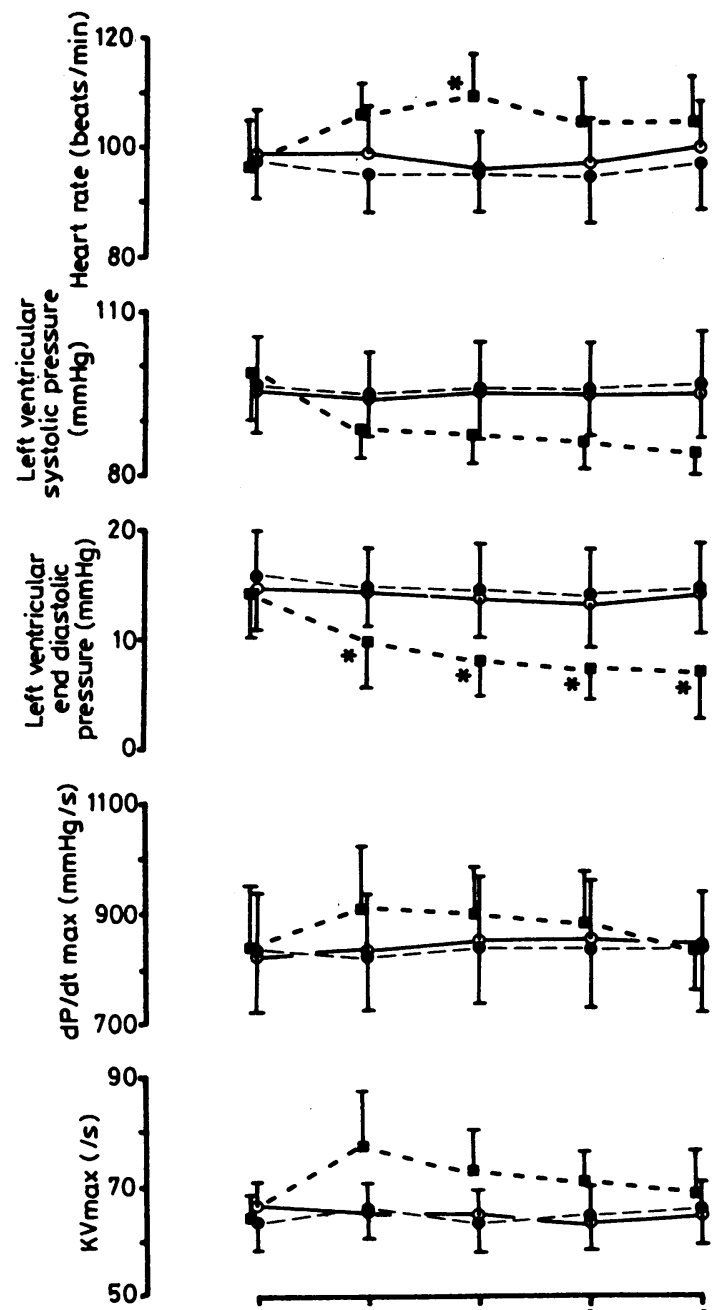

Table 2 Plasma concentrations of amrinone in peripheral venous blood during acute intravenous and long term oral amrinone treatment

\begin{tabular}{|c|c|c|c|c|}
\hline $\begin{array}{l}\text { Route of } \\
\text { administration }\end{array}$ & Dose & $\begin{array}{l}\text { Frequency of } \\
\text { administration }\end{array}$ & $\begin{array}{l}\text { Interoal since } \\
\text { last dose }\end{array}$ & $\begin{array}{l}\text { Range (mean) plasma anerinone } \\
\text { concentrations ( } \mu \mathrm{g} / \mathrm{ml})\end{array}$ \\
\hline Intravenous & $1.5 \mathrm{mg} / \mathrm{kg}$ & Once only & $\left\{\begin{array}{l}0-5 \min \\
6-10 \mathrm{~min}\end{array}\right.$ & $\begin{array}{l}4-13 \\
3-5\end{array}$ \\
\hline Intravenous & $3.5 \mathrm{mg} / \mathrm{kg}$ & Once only & & $\begin{array}{l}\leqslant 28 \\
5-9\end{array}$ \\
\hline Oral & $100 \mathrm{mg}$ & Every 8 hours & $\left\{\begin{array}{l}2 \mathrm{~h} \text { (peak) } \\
8 \mathrm{~h} \text { (trough) }\end{array}\right.$ & $\begin{array}{l}0.5-6.4(3.0) \\
0-5.1(1.9)\end{array}$ \\
\hline
\end{tabular}

Fig. 1 Effects of short (two minutes) intracoronary infusion of lactate (O-O) and amrinome (O-.-) and of intravenous left ventricular function. Infusions were administered after taking basal measurements ( 0 minutes) until after taking measurements at two minutes. Values shown are mean $(S E M) .{ }^{\star} p<0.05$. amrinone $(\square-2)$ on haemodymamics in six patients with poor 

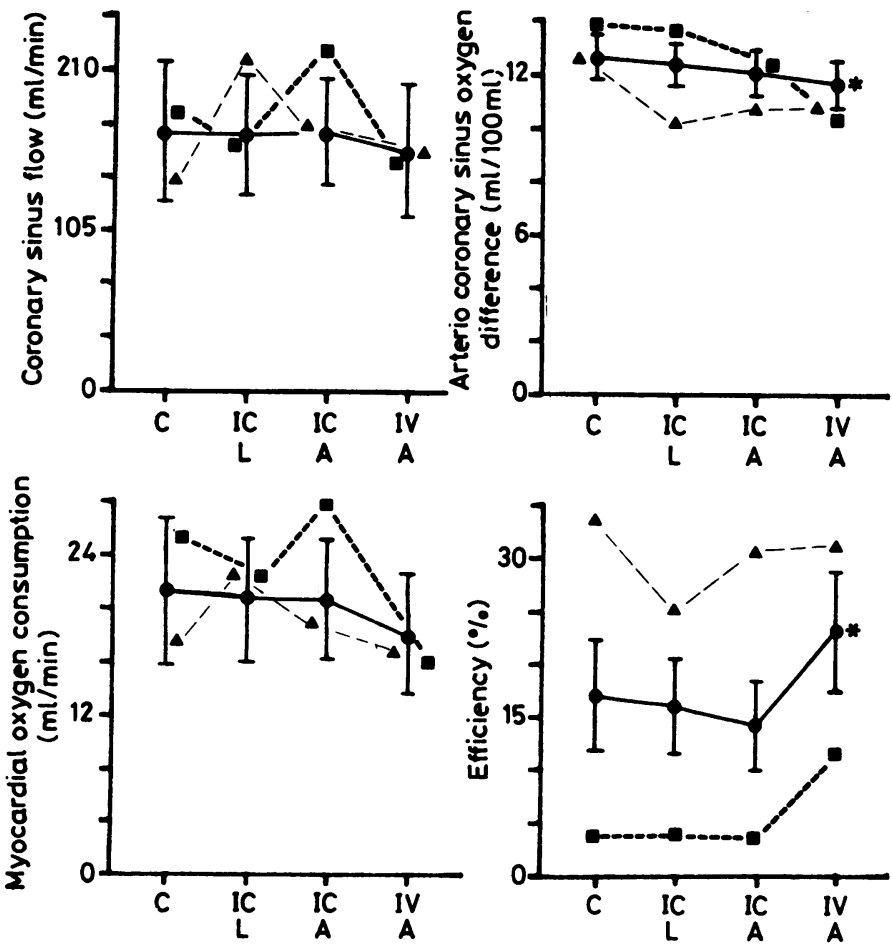

Fig. 2 Effects of intracoromary and intravenous administration of amrinone on coromary sinus flow, arteriocoronary sinus oxygen difference, myocardial oxygen consumption, and myocardial efficiency in six patients with poor left ventricular function who received short (two minute) intracoronary infusions (mean (SEM)) (O--O) and the two patients who received long intracoronary infusions, one with good ( $\Delta--\Delta)$ and one with poor (D--D) left ventricular function. $C$, control; $L$, lactate; $A$, amininone; IC, intracoronary; $I V$, intravenous. $\star p<0.05$.

seen for any variable measured except that left ventricular ejection fraction was slightly but significantly reduced after intracoronary infusion of amrinone. In addition, coronary vascular resistance was unaltered in one patient after the short intracoronary infusion of amrinone and reduced in the remaining five compared with intracoronary lactate, but the mean value failed to achieve significance (Fig. 5).

In contrast, in these six patients intravenous amrinone produced a significant $(p<0.05)$ increase in heart rate at four minutes and a significant $(p<0.05)$ reduction in left ventricular end diastolic pressure at all times after the intervention (Fig. 1). The reduction in left ventricular systolic pressure after intravenous amrinone just failed to achieve significance at all times shown $(0.05<p<0.1)$. Slight increases in indices of contractility were seen but did not achieve significance when compared with control data and measurements made at the same intervals after the intracoronary infusion of lactate. Intravenously infused amrinone also produced significant reductions in arteriocoronary sinus oxygen difference, left ventricular end diastolic volume index, pulmonary arterial and aortic pressures, and systemic vascular resistance and produced increases in cardiac index, left ventricular ejection fraction, left ventricular minute work, and efficiency (Figs. 2, 3, and 4). Coronary sinus flow, myocardial oxygen consumption, pulmonary and coronary vascular resistances, and the left ventricular end systolic pressure to volume ratio were not significantly altered.

\section{Metabolism}

The short intracoronary infusion of lactate produced a significant increase in arterial pyruvate concentration, myocardial pyruvate extraction, and myocardial pyruvate extraction ratio compared with control values. Intracoronary amrinone produced a significant increase in myocardial pyruvate extraction, but the increases in arterial pyruvate concentration and 

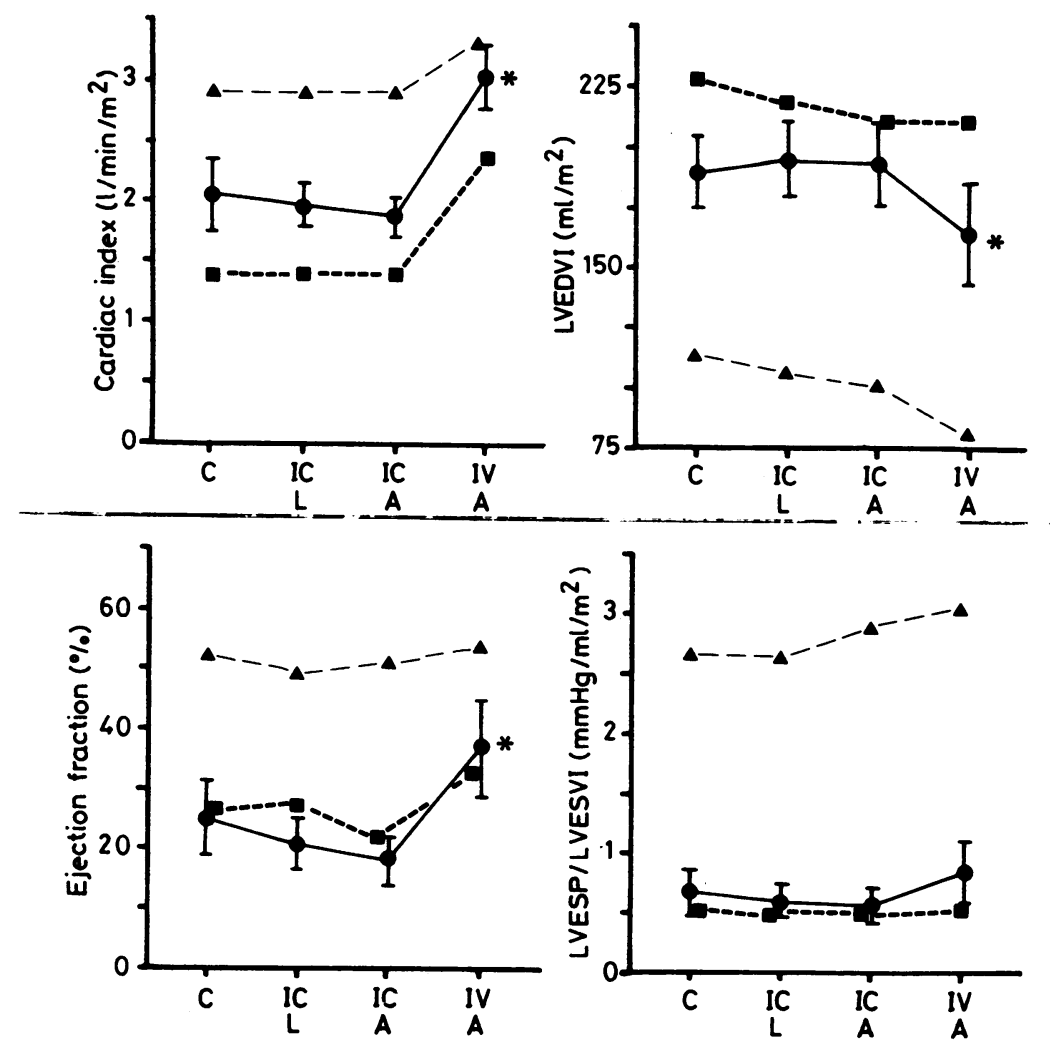

Fig. 3 Effects of intracoronary and intravenous infusion of amerinone on cardiac index, left ventricular end diastolic volume index (LVEDVI), lefi ventricular ejection fraction, and lefi ventricular end systolic pressure toolume index (LVESP/LVESVI) in six patients with poor left ventricular function who received short (two minute) intracoromary infusions (mean (SEM)) (-) and two patients who received long intracoronary infusions, one with poor ( $\square--\square)$ and one with good ( $\Delta-\cdots)$ left ventricular function. C, control; $L$, lactate; $A$, amrinone; IC, intracoronary; $I V$, intravenous. ${ }^{\star} p<0.05$.

myocardial pyruvate extraction ratios were not significant compared with control values. The effects of intracoronary lactate and intracoronary amrinone on pyruvate metabolism were not significantly different. Intravenous amrinone had no significant effect on pyruvate metabolism (Table 3).

Short intracoronary infusions of both amrinone and lactate and the administration of intravenous amrinone in these six patients had no significant effect on arterial or coronary sinus concentrations, myocardial extractions, or extraction ratios of lactate, glycerol, free fatty acid (Table 3 ), or ketone bodies (not tabulated). The mean arterial plasma concentrations of glycerol and free fatty acid rose after intravenous administration of amrinone because considerable increases $(>40 \%)$ developed in two patients.

Samples of plasma for estimation of glucose con- centration were unfortunately destroyed in two of the six patients who received the short intracoronary infusions. In the remaining four patients intracoronary infusions produced no detectable effect on the arterial or coronary sinus concentrations of glucose. A small effect could have been masked by the general tendency for the arterial glucose concentration to decline with time (presumably the result of fasting). In each patient, however, intravenous amrinone produced a rise in arterial and coronary sinus glucose concentration compared with the preceding estimation. The mean increase for both arterial and coronary sinus concentrations was $1.2 \mathrm{mmol} / \mathrm{l}$.

\section{LONG INFUSIONS \\ Haemodymamics}

The patient with dilated cardiomyopathy who 

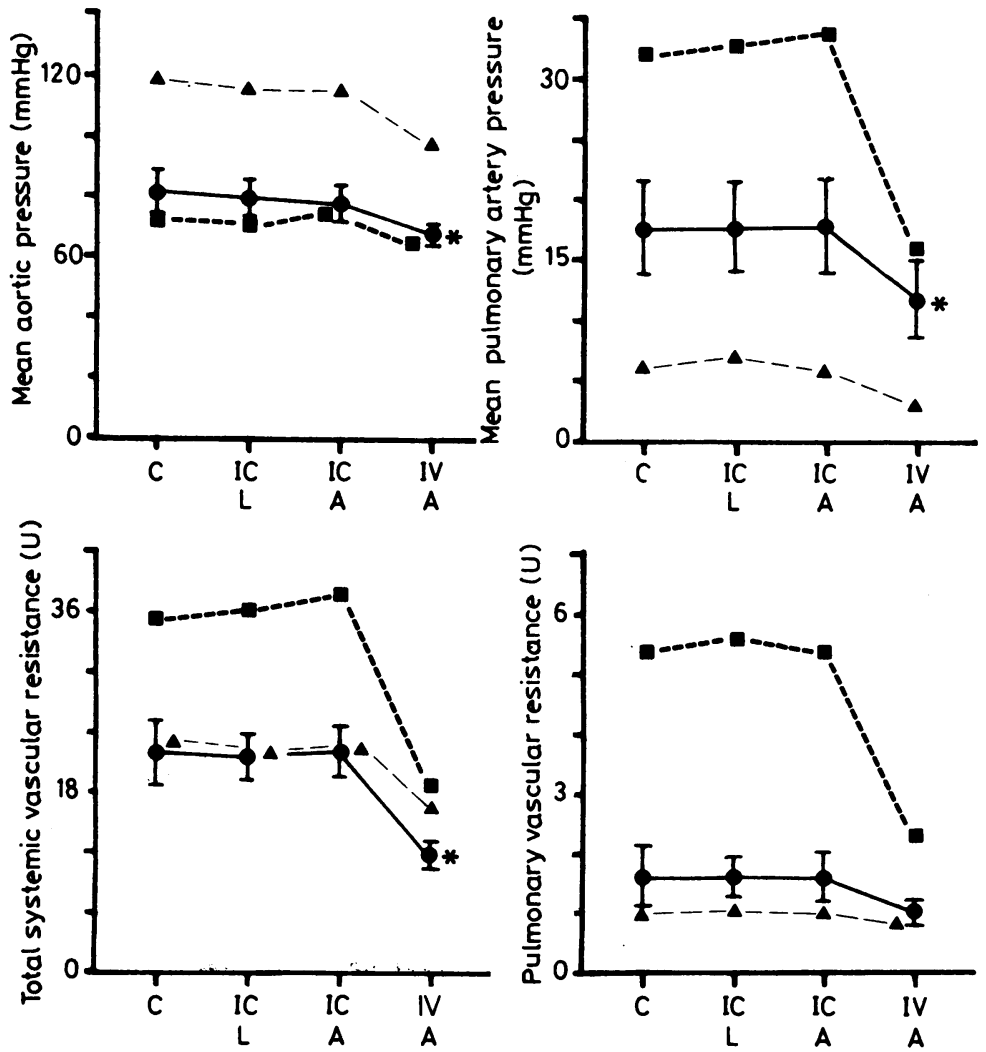

Fig. 4 Effects of intracoromary and intravenous infusion of amarinone on mean aortic pressure, mean pulmonary artery pressure, total systemic vascular resistance, and pulmonary vascular resistance in six patients with poor left ventricular function who received short (two minute) intracoronary infusions (mean $(S E M))(-0)$ and two patients who received long intracoronary infusions, one with poor (.$--\square)$ and one with good ( $\Delta---\Delta)$ left ventricular function. $C$, control; $L$, lactate; $A$, amrinone; $I C$, intracoronary; $I V$, intravenous. ${ }^{\star} p<0.05$.

received the long intracoronary infusions had preintervention haemodynamic indices comparable to or slightly worse than those for the six patients who received the short intracoronary infusions. The other patient who received long intracoronary infusions had good left ventricular function as judged from heart rate, filling pressures, cardiac index, left ventricular ejection fraction, and indices of contractility.

In both patients when compared with values in the control state and during intracoronary infusion of lactate the long intracoronary infusion of amrinone did not cause any consistent alteration in left ventricular pressures or indices of contractility (Figs. 6 and 7), cardiac index or variables derived from left ventricular angiography (Fig. 3), pulmonary arterial and aortic pressures, left ventricular minute work, or systemic or pulmonary vascular resistances (Fig. 4). In the patient with poor left ventricular function coronary sinus flow increased and coronary vascular resistance fell after intracoronary infusion of amrinone, but opposite changes were seen in the patient with good left ventricular function (Figs. 2 and 5).

After receiving intravenous amrinone the patient with poor left ventricular function showed a transient rise in heart rate (maximum four minutes after the start of the infusion) and a later reduction in left ventricular filling pressure (Fig. 6). Contractility indices were increased in this patient after the intravenous dose of amrinone, although no improvement in contractility had been seen during the intracoronary amrinone infusion. Changes in other haemodynamic indices - for example, heart rate, blood pressures, and flows-after intravenous amrinone in this patient, however, were comparable with those observed after 


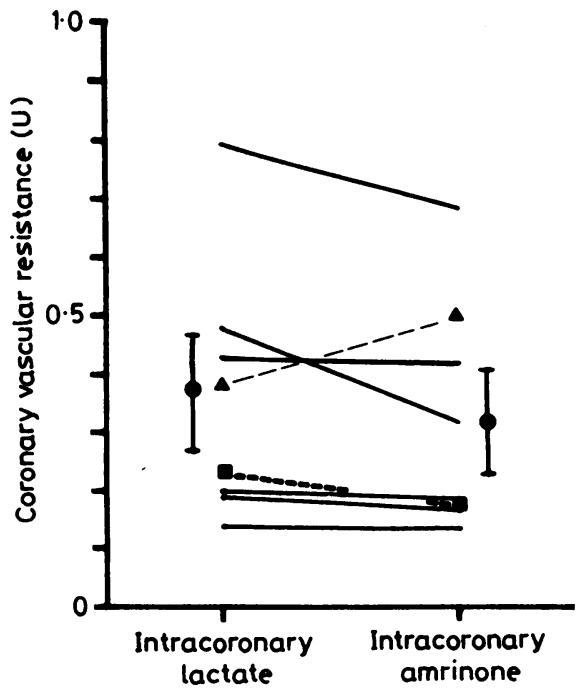

Fig. 5 Effect of intracoromary amrinone on coronary vascular resistance in six patients who received short (two minute) intracoronary infusions (- $\longrightarrow$ (mean $(S E M)$ for all six represented by $O$ ) and two patients who received long intracoronary infusions, one with poor left ventricular function (D---D) and one with good left ventricular function ( $\Delta---\Delta)$.

intravenous amrinone in the six patients who received short intracoronary infusions (Figs. 2, 3, and 4).
The responses seen after intravenous amrinone in the seven patients with poor left ventricular function differed a little from those observed in the patient with good left ventricular function. In this patient a reduction in left ventricular pressures also occurred, but the decrease in left ventricular systolic pressure was considerable (Fig. 7). This was accompanied by a large increase in heart rate and contractility indices (Fig. 7). The slight increase in cardiac index seen was due to the increase in heart rate, as left ventricular end diastolic volume and ejection fraction were unaltered (Fig. 3). Pulmonary arterial and aortic pressures and systemic vascular resistance were considerably reduced after intravenous amrinone (Fig. 4). In contrast to the changes in arteriocoronary sinus oxygen difference, left ventricular minute work, and efficiency observed after intravenous amrinone in the patients with poor left ventricular function, a slight reduction in minute work and no real alteration in efficiency or arteriocoronary sinus oxygen difference developed in the patient with good left ventricular function (Fig. 2).

\section{Metabolism}

The metabolic effects of the long intracoronary infusions of amrinone and the lactate solution are difficult to determine as during the periods of sampling for metabolites both the subjects were receiving an

Table 3 Metabolic effects of interventions in patients who received short intracoronary infusions. Figures are mean (SEM) values

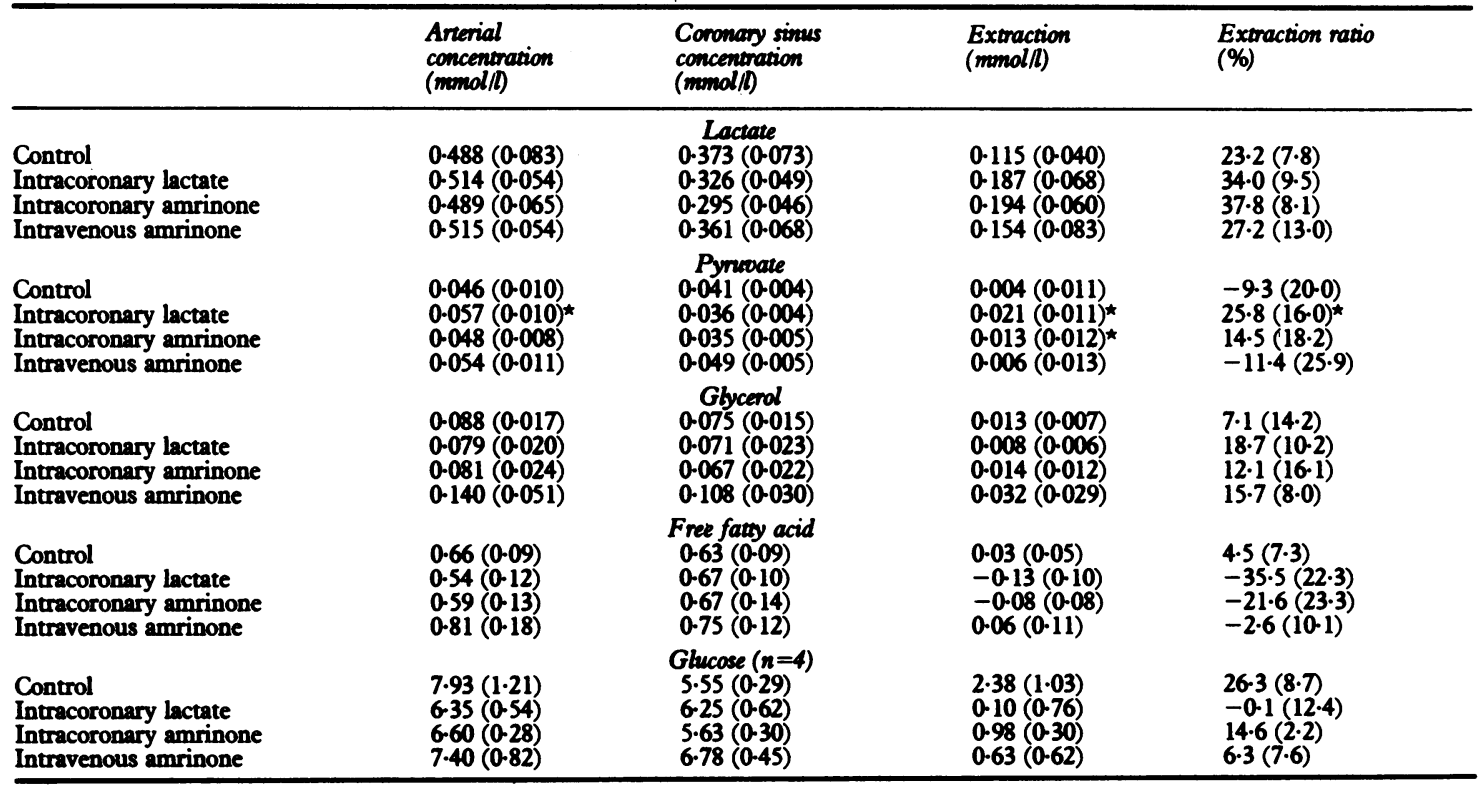

*Significance compared with control $p<0.05$.

Conversion: SI to traditional units-Lactate: $1 \mathrm{mmol} \approx 90 \mathrm{mg}$. Pyruvate: $1 \mathrm{mmol} \approx 88 \mathrm{mg}$. Glycerol: $1 \mathrm{mmol} \approx 217 \mathrm{mg}$. Glucose: $1 \mathrm{mmol} \approx$ $180 \mathrm{mg}$. 

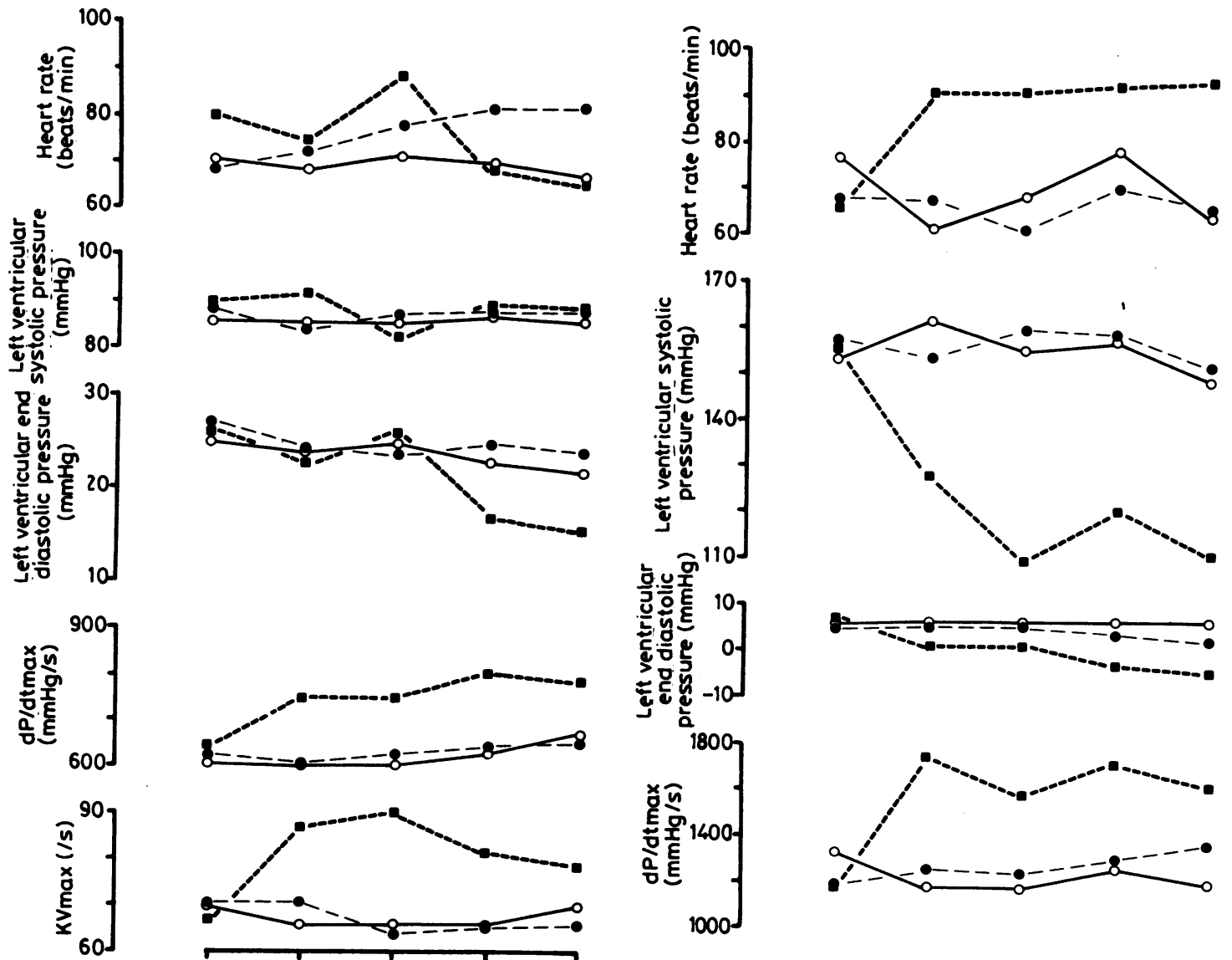

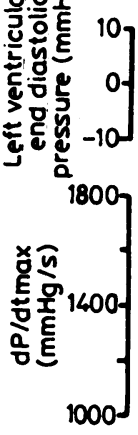
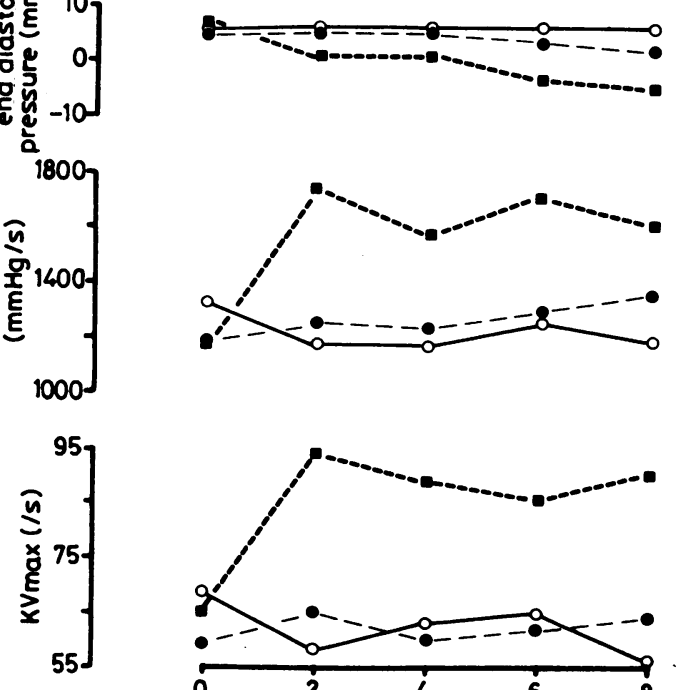

Fig. 6 Effect of long intracoronary infusion of lactate $(O-O)$ and amrinone (---O) and intravenous infusion of amainone (口---D) on haemodymamics in the patient with poor left ventricular function. Infusions were administered after taking basal measurements ( 0 minutes).

intracoronary lactate load from the infusion itself. It was thus difficult to know precisely the lactate concentration of blood flowing down the left coronary artery. This would be dependent on the lactate concentrations in arterial blood and the infusion solutions and the relative contribution of each of these to the blood in the left coronary artery. These factors would also influence, to a lesser extent, the concentrations of other metabolites in the left coronary artery. (As the volume of infusate per minute was small compared with coronary sinus flow rate it should introduce only a small or negligible volume effect to changes in myocardial oxygen consumption occurring as a result of pharmacological properties of the infusate.) The analysis of coronary sinus blood during these long

Fig. 7 Effect of long intracoronary infusion of lactate $(\mathrm{O}-\mathrm{O})$ and amerinone (-.--) and intravenous infusion of amrinone (D---D) on haemodymamics in the patient with good left ventricular function. Infusions were administered afier taking basal measurements ( 0 minutes).

infusions showed high concentrations of all myocardial metabolites measured, particularly lactate (Table 4); but the amrinone and lactate infusions had similar effects.

After the subsequent intravenous dose of amrinone, arterial lactate concentrations were altered little, although the myocardial lactate extraction ratio became negative in the patient with good left ventricu- 
Table 4 Metabolic effects of interventions in patients who received long term intracoronary infusions

\begin{tabular}{|c|c|c|c|c|c|c|c|c|}
\hline & \multicolumn{4}{|c|}{ Patient with poor left ventricular function } & \multicolumn{4}{|c|}{ Patient with good left ventricular function } \\
\hline & $\begin{array}{l}\text { Arterial } \\
\text { concentration } \\
\text { (mmollt) }\end{array}$ & $\begin{array}{l}\text { Coronary sinus } \\
\text { concentration } \\
\text { (mimol/l) }\end{array}$ & $\begin{array}{l}\text { Extraction } \\
\text { (momol/l) }\end{array}$ & $\begin{array}{l}\text { Exaraction } \\
\text { ratio } \\
(\%)\end{array}$ & $\begin{array}{l}\text { Arterial } \\
\text { concentration } \\
\text { (menol/l) }\end{array}$ & $\begin{array}{l}\text { Coronary simus } \\
\text { concentration } \\
\text { (mamolll) }\end{array}$ & $\begin{array}{l}\text { Extraction } \\
\text { (mmol/l) }\end{array}$ & $\begin{array}{l}\text { Extraction } \\
\text { ratio } \\
\text { (\%) }\end{array}$ \\
\hline $\begin{array}{l}\text { Control } \\
\text { Intracoronary lactate } \\
\text { Intracoronary amrinone } \\
\text { Intravenous amrinone }\end{array}$ & $\begin{array}{l}0.560 \\
0.567 \\
0.575 \\
0.654\end{array}$ & $\begin{array}{l}0.366 \\
0.451 \\
0.412 \\
0.610\end{array}$ & $\begin{array}{l}0.194 \text { Lact } \\
\text { NC } \\
\text { NC } \\
0.044\end{array}$ & $\begin{array}{l}\text { ate } \\
34.6 \\
\text { NC } \\
\text { NC } \\
6.7\end{array}$ & $\begin{array}{l}0.299 \\
0.242 \\
0.279 \\
0.256\end{array}$ & $\begin{array}{l}0.204 \\
0.471 \\
0.274 \\
0.263\end{array}$ & $\begin{array}{l}0.095 \\
N C \\
N C \\
-0.007\end{array}$ & $\begin{array}{l}31.8 \\
N C \\
N C \\
-2.7\end{array}$ \\
\hline $\begin{array}{l}\text { Control } \\
\text { Intracoronary lactate } \\
\text { Intracoronary amrinone } \\
\text { Intravenous amrinone }\end{array}$ & $\begin{array}{l}0.031 \\
0.035 \\
0.038 \\
0.035\end{array}$ & $\begin{array}{l}0.041 \\
0.045 \\
0.047 \\
0.066\end{array}$ & $\begin{array}{l}\quad \text { Pyrut } \\
-0.010 \\
\text { NC } \\
\text { NC } \\
-0.031\end{array}$ & $\begin{array}{l}-32 \cdot 3 \\
N C \\
N C \\
-88 \cdot 6\end{array}$ & $\begin{array}{l}0.039 \\
0.040 \\
0.044 \\
0.048\end{array}$ & $\begin{array}{l}0.064 \\
0.078 \\
0.038 \\
0.035\end{array}$ & $\begin{array}{l}-0.025 \\
N C \\
N C \\
0.013\end{array}$ & $\begin{array}{l}-64 \cdot 1 \\
\text { NC } \\
\text { NC } \\
27 \cdot 1\end{array}$ \\
\hline $\begin{array}{l}\text { Control } \\
\text { Intracoronary lactate } \\
\text { Intracoronary amrinone } \\
\text { Intravenous amrinone }\end{array}$ & $\begin{array}{l}0.143 \\
0.151 \\
0.159 \\
0.183\end{array}$ & $\begin{array}{l}0.149 \\
0.178 \\
0.157 \\
0.167\end{array}$ & $\begin{array}{l}\quad \text { Glyc } \\
-0.006 \\
\text { NC } \\
\text { NC } \\
0.016\end{array}$ & $\begin{array}{l}\text { rol } \\
-4 \cdot 2 \\
\mathrm{NC} \\
\mathrm{NC} \\
8.7\end{array}$ & $\begin{array}{l}0.143 \\
0.130 \\
0.136 \\
0.152\end{array}$ & $\begin{array}{l}0.164 \\
0.152 \\
0.137 \\
0.152\end{array}$ & $\begin{array}{l}-0.021 \\
N C \\
N C \\
0.000\end{array}$ & $\begin{array}{l}-14 \cdot 7 \\
\mathrm{NC} \\
\mathrm{NC} \\
0.0\end{array}$ \\
\hline $\begin{array}{l}\text { Control } \\
\text { Intracoronary lactate } \\
\text { Intracoronary amrinone } \\
\text { Intravenous amrinone }\end{array}$ & $\begin{array}{l}0.73 \\
0.85 \\
0.75 \\
0.94\end{array}$ & $\begin{array}{l}0.60 \\
0.73 \\
0.79 \\
0.63\end{array}$ & $\begin{array}{l}\text { Free fat } \\
0.13 \\
\text { NC } \\
\text { NC } \\
-0.31\end{array}$ & $\begin{array}{l}y \text { acid } \\
17 \cdot 8 \\
N C \\
N C \\
-33 \cdot 0\end{array}$ & $\begin{array}{l}0.75 \\
0.63 \\
0.66 \\
0.79\end{array}$ & $\begin{array}{l}0.47 \\
0.48 \\
0.51 \\
0.63\end{array}$ & $\begin{array}{l}0.28 \\
\text { NC } \\
\text { NC } \\
0.16\end{array}$ & $\begin{array}{l}37 \cdot 3 \\
\mathrm{NC} \\
\mathrm{NC} \\
20 \cdot 3\end{array}$ \\
\hline $\begin{array}{l}\text { Control } \\
\text { Intracoronary lactate } \\
\text { Intracoronary amrinone } \\
\text { Intravenous amrinone }\end{array}$ & $\begin{array}{l}6.6 \\
\star \\
7.6 \\
8.6\end{array}$ & $\begin{array}{l}6.2 \\
6.5 \\
6.4 \\
6.8\end{array}$ & $\begin{array}{l}0.4 \\
\text { NC } \\
\text { NC } \\
1.8\end{array}$ & $\begin{array}{l}\text { ose } \\
6.1 \\
\text { NC } \\
\text { NC } \\
20.9\end{array}$ & $\begin{array}{l}6.3 \\
5.4 \\
5.6 \\
5.5\end{array}$ & $\begin{array}{l}4.5 \\
4.5 \\
4.9 \\
4.9\end{array}$ & $\begin{array}{l}1.8 \\
\text { NC } \\
0.6\end{array}$ & $\begin{array}{l}28.6 \\
\text { NC } \\
\text { NC } \\
10.9\end{array}$ \\
\hline
\end{tabular}

*Broken.

NC, not calculable.

Conversion: SI to traditional units-Lactate: $1 \mathrm{mmol} \approx 90 \mathrm{mg}$. Pyruvate: $1 \mathrm{mmol} \approx 88 \mathrm{mg}$. Glycerol: $1 \mathrm{mmol} \approx 217 \mathrm{mg}$. Glucose: $1 \mathrm{mmol} \approx$ $180 \mathrm{mg}$.

lar function (Table 4). Increases in the arterial concentrations of glycerol, free fatty acid, glucose (Table 4), hydroxybutyrate, and acetoacetate (not tabulated) were seen after intravenous amrinone in both patients. These changes were more pronounced in the patient with poor left ventricular function (glucose concentration being compared with the glucose concentration during the preceding intervention).

\section{Interrelations between variables measured}

After intracoronary drug infusions we were unable to detect any relation between coronary sinus amrinone concentrations and haemodynamic or metabolic changes observed. Removal of the one or two patients with the lowest coronary sinus amrinone concentrations does not materially affect mean values or the overall analysis of data.

Patients who received short or long intracoronary infusions received different total doses of the drugs by this route. They all subsequently received the same dose of amrinone $(1.5 \mathrm{mg} / \mathrm{kg})$ by the intravenous route. It was thus possible to analyse the haemodynamic effects of intravenous amrinone in these eight patients combined. No relation was found between alterations in contractility and plasma concentrations of amrinone or $N$-acetyl amrinone. As in a previous study ${ }^{3}$ we sought a relation between alterations in haemodynamics and metabolic changes after intravenous amrinone. The percentage increase in arterial free fatty acid concentration was linearly related to percentage increase in $\mathrm{dP} / \mathrm{dt} \max$ $(y=7.83+0.38 x, n=8, r=0.64)$, although the relation just failed to achieve significance $(0.05<\mathrm{p}<0.1)$.

An inverse relation existed between control left ventricular ejection fraction (\%) and percentage increase in ejection fraction after intravenous amrinone $(y=96.1-1.64 x, n=8, r=0.714, p<0.05)$. In fact, a relation existed between a number of baseline (control) haemodynamic variables and the response to intravenous amrinone, although not to intracoronary amrinone.

We arbitrarily divided the patients into two groups of four; those with a normalised left ventricular end diastolic volume $>200$ (range $209-241$, mean 222 ) $\mathrm{ml} / \mathrm{m}^{2}$ and those with a volume index $<200$ (range 112-183, mean 148$) \mathrm{ml} / \mathrm{m}^{2}$. Those patients with the larger left ventricular end diastolic volumes had lower control mean aortic pressures (57-78 v 85-119 mm Hg), higher left ventricular end diastolic pressures (19-27 $v$ 4-9 mm Hg), lower dP/dt max (467-780 v 913-1154 $\mathrm{mm} \mathrm{Hg} / \mathrm{s})$, lower left ventricular end systolic pressure/volume indexes $(0.26-0.49 v 0.63-2.65 \mathrm{~mm}$ 
$\mathrm{Hg} / \mathrm{ml} / \mathrm{m}^{2}$ ), and lower left ventricular minute work $(1.17-3.51$ v $5.64-9.66 \mathrm{~kg} \mathrm{~m} / \mathrm{min})$ as well as generally lower efficiency (2.1-28.6, mean $10.9 v 8.8-35.1$, mean $23.7 \%$ ), cardiac indices (1.1-2.0, mean 1.6 $v 1.8-3.2$, mean $2.61 / \mathrm{min} / \mathrm{m}^{2}$ ), and ejection fractions (6-26, mean 17 v 21-52, mean 39\%). The two groups had similar resting heart rates, arteriocoronary sinus oxygen differences, coronary sinus flow rates, myocardial oxygen consumptions, and lactate extractions. After intravenous amrinone filling pressures fell by similar amounts in each group, but aortic pressure fell less in the group with the larger left ventricular volumes ( $5 v 22 \mathrm{~mm} \mathrm{Hg}$ ). In the patients with the larger ventricular volumes heart rate was unchanged after amrinone but rose in the other group (range 11-24 (mean 16) beats/min). Cardiac index rose in both groups after intravenous amrinone, but this increase was greater in the group with the larger left ventricular volume in both absolute (0.9-2.2 (mean 1.4) $v 0.2-1.0$ (mean 0.5) $1 / \mathrm{min}$ ) and relative terms (45-122\% (mean $89 \%$ ) v 8-56\% (mean 23\%)). Left ventricular minute work fell after intravenous amrinone in three of the group with the smaller left ventricular volumes, and efficiency was reduced in two, but both variables were improved in each of the four patients with larger left ventricular volumes. In each of the patients with smaller left ventricles, but not in the other group, the left ventricular end systolic pressure/volume index rose appreciably after amrinone. This change, however, was accompanied by a large increase in heart rate in each patient and was not accompanied by consistent alterations in pressure derived contractility indices.

\section{Discussion}

Amrinone possesses undoubted positive inotropic properties in myocardium from normal animals and animals with acutely induced cardiac failure. ${ }^{45}$ This property is at least partly the result of phosphodiesterase inhibitory activity 2122 and partly due to potentiation of the effects of catecholamines on the myocardium. ${ }^{21}$ In chronic cardiac failure in myocardium from animals ${ }^{23}$ and $\operatorname{man}^{6}$ the direct positive inotropic effects of amrinone disappear. Even in normal myocardium the concentrations of amrinone required to produce a direct positive inotropic effect are considerably higher than those that can be obtained during long term oral treatment ${ }^{24-26}$ because of common, severe, and dose related adverse effects. 252728 Amrinone also possesses powerful direct vasodilator properties in animal and human vessels 5629 and may also cause systemic catecholamine release in some cases by mechanisms independent of reflex changes resulting from vasodilatation. ${ }^{3}$

This study is an attempt to prevent these peripheral vascular effects and systemic alterations of autonomic or neuroendocrine activity from masking the cardiac effects of amrinone. These cardiac properties could include effects on coronary vessels, cardiac nerves, and myocardial neurotransmitter potentiation, as well as direct effects on myocardial cells themselves.

Intracoronary administration of any drug solution will have effects that are due to partial replacement of coronary perfusing blood by nutrient poor, nonoxygenated solvent as well as those effects due to the pharmacological properties of the drug itself. Consequently, it was necessary to investigate the effect of the solvent (lactate solution) itself in each patient studied. To prevent an order effect the intracoronary infusions were administered in a randomised crossover manner. The patients and the technicians performing biochemical analysis were unaware of intervention order, and haemodynamic measurements were made by computer. Thus, although the doctors giving the drugs were aware of the order of administration of the infusions (which were different colours) selection and biased interpretation of data were prevented. This technique contrasts appreciably with earlier "titration" studies of the haemodynamic effects of amrinone, in which peak effects and predetermined haemodynamic end points were employed. ${ }^{7-9}$ Such studies cannot be used to argue that a drug possesses a particular effect, although the magnitude and time course of that effect can be assessed, provided that the effect has already been adequately shown to be present.

We initially investigated the effect of short intracoronary infusions lasting two minutes. During in vitro experiments exposure of myocardium to amrinone is accompanied by a rapid increase in tension development, which reaches a plateau within two minutes in tissue from both animals ${ }^{5}$ and man (unpublished observations). An infusion for two minutes should be an adequate interval for increases in tension to occur if the tissue is responsive and provided that adequate concentrations of amrinone are achieved. To confirm that there were adequate concentrations coronary sinus blood was sampled during the infusions. We also continued observation of haemodynamics after the intracoronary infusion in case late changes occurred.

We administered the drug into the left coronary artery alone, aware that our failure to administer the drug also into the right coronary artery might produce a steal phenomenon or regional dyskinesia. We thought, however, that it would not be justified to cannulate both coronary ostia. The rate of drug infusion was $0.5 \mathrm{mg} / \mathrm{min}$, which we had estimated from mean coronary flows, would produce concentrations of drug in coronary sinus blood in the range of those detected in peripheral blood during long term oral 
treatment. (We have previously found an incidence of thrombocytopenia greater than $50 \%$ in patients receiving long term oral treatment when mean plasma amrinone concentration exceeds $2.5 \mu \mathrm{g} / \mathrm{ml},{ }^{26}$ so we aimed to achieve coronary sinus concentrations of the drug that were lower than this.) We also predicted that unexpected adverse reactions to the intracoronary drug infusions would be unlikely to develop as the concentrations of drug achieved would be lower than those we found in the circulation during the initial five minutes after bolus adminstration of amrinone. These predictions proved accurate.

After this group of six preliminary experiments we intended to proceed to a series of further experiments in which the intracoronary infusions were considerably prolonged in case the occurrence of any inotropic effect of amrinone in vivo is delayed. It was our intention to investigate the effect of long infusions in at least six patients with dilated cardiomyopathy and in as many patients as might prove practical with normal coronary arteries and good left ventricular function who required investigation of myocardial lactate metabolism. We were unable to complete these experiments owing to the manufacturers' action.

In all patients, whether they received long or short intracoronary infusions, the effect of intravenous amrinone was also investigated. This was to confirm that these patients did not respond in an atypical manner to intravenous amrinone, which might for example have explained a surprising response to intracoronary amrinone. In fact the responses of the patients to intravenous amrinone were totally as expected. A reduction in left ventricular filling pressure and an increase in cardiac index occurred in each of the eight patients. The responses of the seven patients with dilated cardiomyopathy to intravenous amrinone were in keeping with our previously published experience. ${ }^{310}$ The response of the patient with good left ventricular function-that is, appreciable reduction in aortic pressure, increase in heart rate, and impaired myocardial lactate extractioncompared well with that seen in other studies in patients with good left ventricular function. ${ }^{3031}$ In this patient the appreciable increases in contractility indices after intravenous amrinone may have been due to the large increase in heart rate or to catecholamine release as a result of vasodilatation, although a direct positive inotropic effect cannot be excluded. The absence, however, of increased contractility during intracoronary infusion of amrinone in this patient does not support the view that he was able to produce a direct positive inotropic response to amrinone at the concentrations achieved during long term oral treatment.

In this study little evidence was detected that intracoronary amrinone (or the lactate) had any effect on haemodynamics or myocardial metabolism. In particular, it was found that the drug produced no alteration in myocardial contractility during either short or long infusions. After the short intracoronary infusion of amrinone, left ventricular ejection fraction was actually reduced compared with intracoronary lactate. A similar reduction occurred after the long intracoronary infusion of amrinone in the patient with poor left ventricular function but not in the patient with good function. These differences were, however, small and are probably not clinically important even though significant.

Coronary vascular resistance was reduced by the short intracoronary infusions of amrinone in five of the six patients studied and unaltered in the other. Coronary vascular resistance was also reduced in the patient with poor left ventricular function who received the long infusion but increased in the patient with good function. The changes in coronary vascular resistance were detectable after the short amrinone infusion despite an interval of six minutes since the end of the infusion. The reduction in coronary vascular resistance after intracoronary amrinone in patients with poor left ventricular function, although not significant, may be clinically important. These observations are in accord with the reductions in arteriocoronary sinus oxygen difference after intravenous amrinone in this study as well as in similar patients in other studies. ${ }^{23}$ It suggests that amrinone may have a direct coronary vasodilator effect in patients with poor left ventricular function similar to that described in animal models. ${ }^{32}$ It also supports the observations that in vitro the vasodilator effects of amrinone are detectable at lower concentrations than the inotropic effects in both human and animal models. ${ }^{6}$

The increase in coronary vascular resistance seen during the long intracoronary infusion of amrinone in the patient with good left ventricular function is surprising. A possible cause might be that patients with poor left ventricular function have relatively low cardiac stores of catecholamine. Thus coronary vessels in such patients are able to respond by direct vasodilatation to amrinone without a major effect from amrinone induced catecholamine release. In the patient with good left ventricular function intracoronary amrinone should also have tended to produce direct vasodilatation, but this might have been masked by vasoconstriction produced by amrinone induced catecholamine release. Nevertheless, during the intracoronary infusion of amrinone the patient with good left ventricular function showed no evidence of an increase in contractility, which might have been expected if cardiac catecholamine stores were being liberated, and this hypothesis cannot easily be tested. 
In the present study we did find evidence to support the view that intravenous amrinone can produce systemic release of catecholamine. As in a previous study, we showed that, although contractility did not increase for the group as a whole after intravenous amrinone, changes in contractility in individual patients were related to metabolic alterations (increased free fatty acid, glycerol, and glucose concentrations), which suggests that they might be the result of catecholamine release. ${ }^{333}$ Indeed, in the present study the metabolic changes after $1.5 \mathrm{mg} / \mathrm{kg}$ intravenous amrinone were identical to those we have previously described in a similar group of patients after the same dose of the intravenous drug. ${ }^{3}$

We also showed that improvements in left ventricular ejection fraction after intravenous amrinone were inversely related to control ejection fraction. The most beneficial changes in other haemodynamic and metabolic variables after the drug were found in the patients with the worst control haemodynamic values. These findings alone would suggest that the effects of intravenous amrinone in cardiac failure are predominately the result of altered loading, even if the effects of intracoronary infusion of amrinone had been less convincing.

Overall these findings agree with our previous observations that in patients with chronic heart failure improvements in haemodynamics after intravenous amrinone are the result of vasodilatation with no evidence of a direct positive inotropic effect. ${ }^{310}$ In such patients any improvement seen in contractility is likely to be due to the release of catecholamine. ${ }^{3}$

In patients with milder degrees of heart failure an additional direct positive inotropic effect with high concentrations of amrinone cannot be entirely excluded. If present in such a patient, however, this effect coupled with the drug's powerful vasodilator properties might prove disadvantageous because the possible increase in heart rate coupled with excessive reductions in preload, coronary perfusion pressure, and myocardial efficiency may worsen myocardial ischaemia, without the benefit of an appreciable increase in cardiac index.

The intracoronary infusions confirmed that at concentrations of the drug likely to be achieved without adverse effects during long term oral treatment (that is, $<2.5 \mu \mathrm{g} / \mathrm{ml}^{26}$ ) amrinone has no positive inotropic effects in human myocardium whether it is from patients with heart failure or nearly normal subjects.

This study highlights the dangers of extrapolating from experiments using very high concentrations of drugs in isolated normal animal myocardium to lower (non-toxic) concentrations in the intact patient, without giving sufficient consideration to additional direct and indirect effects they may have on vessels and the neuroendocrine systems.
We thank C M Miles and J L Evans for their technical help.

This study was supported by grants from the St Thomas's Hospital Cardiac Research Fund and the St Thomas's Hospital Endowment Committee.

\section{References}

1 LeJemtel TH, Keung E, Sonnenblick EH, et al. Amrinone: a new non-glycosidic, non-adrenergic cardiotonic agent effective in the treatment of intractable myocardial failure in man. Circulation 1979; 59: 10981104.

2 Benotti JR, Grossman W, Braunwald E, Carabello BA. Effects of amrinone on myocardial energy metabolism and hemodynamics in patients with severe congestive heart failure due to coronary artery disease. Circulation 1980; 62: 28-34.

3 Wilmshurst PT, Thompson DS, Juul SM, Jenkins BS, Coltart DJ, Webb-Peploe MM. Comparison of the effects of amrinone and sodium nitroprusside on haemodynamics, contractility, and myocardial metabolism in patients with cardiac failure due to coronary artery disease and dilated cardiomyopathy. $\mathrm{Br}$ Heart $\mathcal{F}$ 1984; 52: 38-48.

4 Onuaguluchi G, Tanz RD. Cardiac effects of amrinone on rabbit papillary muscle and guinea-pig Langendorff heart preparations. I Cardiooasc Pharmacol 1981; 3: 1342-55.

5 Alousi AA, Edelson J. Amrinone. In: Goldberg ME, ed. Pharmacological and biochemical properties of drug substances. vol. 3. Washington DC: American Pharmaceutical Association, 1981: 120-47.

6 Wilmshurst PT, Walker JM, Fry CH, et al. Inotropic and vasodilator effects of amrinone on isolated human tissue. Cardiooasc Res 1984; 18: 302-9.

7 Benotti JR, Grossman W, Braunwald E, Davolos DD, Alousi AA. Hemodynamic assessment of amrinone: a new inotropic agent. $N$ Engl f Med 1978; 299: 1373-7.

8 Cárdenas LM, Vidaurri A. Estudio de los efectos hemodinámicos de diferentes dosis de un nuevo inótropico: la amrinona. Arch Inst Cardiol Mex 1979; 49: 961-8.

9 Jennings K, Gwilt D, Crean P, Turnbull S, Gold R, Julian DG. The clinical cardiovascular pharmacology of amrinone. A selective cardiotonic agent. Acta Cardiol (Brux) 1982; suppl 28: 67-75.

10 Wilmshurst PT, Thompson DS, Jenkins BS, Coltart DJ, Webb-Peploe MM. Haemodynamic effects of intravenous amrinone in patients with impaired left ventricular function. Br Heart $\mathcal{F}$ 1983; 49: 77-82.

11 Wilmshurst PT, Thompson DS, Jenkins BS, Coltart DJ, Webb-Peploe MM. Haemodynamic effects of intravenous amrinone in patients with impaired left ventricular function [Letter]. Br Heart $\mathcal{F}$ 1983; 50: 107-8.

12 Wilmshurst PT, Webb-Peploe MM. Side-effects of amrinone therapy [Letter]. Br Heart $\mathcal{F}$ 1983; 50: 499 500.

13 Hermiller JB, Leithe ME, Magorien RD, Unverferth DV, Leier CV. Amrinone in severe congestive heart fail- 
ure: another look at an intriguing new cardioactive drug. f Pharmac Exp Ther 1984; 228: 319-26.

14 Thompson DS, Naqvi N, Juul SM, Coltart DJ, Jenkins BS, Webb-Peploe MM. Haemodynamic and metabolic effects of atenolol in patients with angina pectoris. $\mathrm{Br}$ Heart f 1980; 43: 668-79.

15 Veragut UP, Krayenbühl HP. Estimation and quantification of myocardial contractility in the closedchest dog. Cardiologia 1965; 47: 96-112.

16 Yang SS, Bentivoglio LG, Marãnhao V, Goldberg $H$. From cardiac catheterization data to hemodymamic parameters. 2nd ed. Philadelphia: FA Davis, 1978: 233-358.

17 Kolettis M, Jenkins BS, Webb-Peploe MM. Assessment of left ventricular function by indices derived from aortic flow velocity. $\mathrm{Br}$ Heart $\mathcal{F}$ 1976; 38: 18-31.

18 Kullberg MP, Dorrbecker B, Lennon J, Rowe E, Edelson J. High performance liquid chromatographic analysis of amrinone and its $\mathrm{N}$-acetyl derivative in plasma: pharmacokinetics of amrinone in the dog. $f$ Chromatogr 1980; 187: 264-70.

19 Thompson DS, Naqvi N, Juul SM, et al. Cardiac work and myocardial substrate extraction in congestive cardiomyopathy. Br Heart f 1982; 47: 130-6.

20 Schlant RC, Sonnenblick EH, Gorlin R. Normal physiology of the cardiovascular system. In: Hurst JW, Logue RB, Rackley CE, et al, eds. The heart, arteries and veins. 5th ed. New York: McGraw Hill, 1982: 75-114.

21 Honerjäger $P$, Schäfer-Korting $M$, Reiter $M$. Involvement of cyclic AMP in the direct inotropic action of amrinone: biochemical and functional evidence. Naunyn Schmiedebergs Arch Pharmacol 1981; 318: 112-20.

22 Endoh M, Yamashita S, Taira N. Positive inotropic effect of amrinone in relation to cyclic nucleotide metabolism in the canine ventricular muscle. $f$ Pharmacol Exp Ther 1982; 221: 775-83.

23 Gaide MS, Fitterman WS, Wiggins JR, Myerburg RJ, Cameron JS, Bassett AL. Amrinone relaxes potassiuminduced contracture of failing right ventricular muscle of cats. F Cardiovasc Pharmacol 1983; 5: 335-40.

24 Baylis J, Norell M, Canepa-Anson R, Reuben SR, Poole-Wilson PA, Sutton GC. Acute haemodynamic comparison of amrinone and pirbuterol in chronic heart failure. Additional effects of isosorbide dinitrate. $\mathrm{Br}$ Heart f 1983; 49: 214-21.

25 Wilmshurst PT, Webb-Peploe MM. Side effects of amrinone therapy. Br Heart $\mathcal{F}$ 1983; 49: 447-51.

26 Wilmshurst PT, Al-Hasani SFA, Semple MJ, et al. The effects of amrinone on platelet count, survival and function in patients with congestive cardiac failure. $\mathrm{Br} \mathcal{f}$ Clin Pharmacol 1984; 17: 317-24.

27 Dunkman WB, Wilen MM, Franciosa JA. Adverse effects of long-term amrinone administration in congestive heart failure. Am Heart f 1983; 105: 861-3.

28 Leier CV, Dalpiaz K, Huss P, et al. Amrinone therapy for congestive heart failure in outpatients with idiopathic dilated cardiomyopathy. Am $\mathcal{F}$ Cardiol 1983; 52: 304-8.

29 Meisheri KD, Palmer RF, Van Breemen C. The effects of amrinone on contractility, $\mathrm{Ca}^{2+}$ uptake and CAMP in smooth muscle. Eur f Pharmacol 1980; 61: 159-65.

30 Prokein E, Oeff M, Linderer T, Schröder R. Vergleichende untersuchung der wirkung von AR-L115 und amrinone auf hamodynamik, kontraktilität und myokardialen sauerstoffverbrauch [Abstract]. Z Kardiol 1983; 72 (suppl 1): 82.

31 Saborowski F, Griebenow R, Sirinyan G, Hense K. Metabolische und hämodynamische befunde nach gabe von amrinone bei patienten mit koronarer herzkrankheit [Abstract]. Z Kardiol 1983; 72 (suppl 1): 81.

32 Millard RW, Dubé G, Grupp G, Grupp I, Alousi A, Schwartz A. Direct vasodilator and positive inotropic actions of amrinone. $\mathcal{H}$ Moll Cell Cardiol 1980; 12: 64752.

33 Weiner N. Norepinephrine, epinephrine and the sympathomimetic amines. In: Gilman AG, Goodman LS, Gilman A, eds. Goodman and Gilmans the pharmacological basis of therapeutics. 6th ed. New York: MacMillan, 1980: 138-75. 